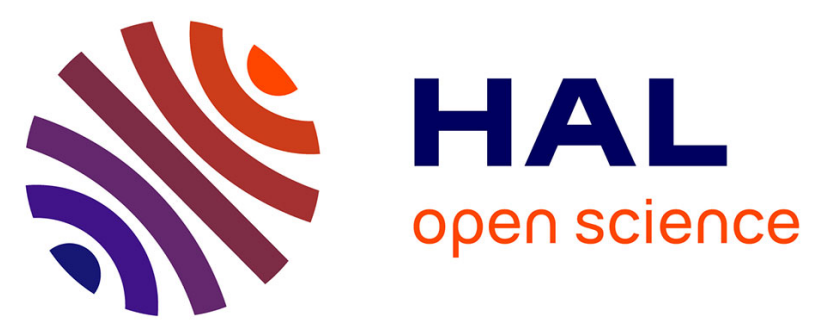

\title{
Mapping nature-based marine flooding risk using VHR wave, airborne LiDAR and satellite imagery: the case study of the Dol Marsh (Bay of Mont-Saint-Michel, France)
}

Antoine Mury, Antoine Collin, Matthieu Jeanson, Dorothée James, Hélène

Gloria, Yves Pastol, Samuel Etienne

\section{To cite this version:}

Antoine Mury, Antoine Collin, Matthieu Jeanson, Dorothée James, Hélène Gloria, et al.. Mapping nature-based marine flooding risk using VHR wave, airborne LiDAR and satellite imagery: the case study of the Dol Marsh (Bay of Mont-Saint-Michel, France). Journal of Coastal Research, 2020, 95, pp.743-747. 10.2112/SI95-145.1 . hal-02946351

\section{HAL Id: hal-02946351 \\ https://hal.science/hal-02946351}

Submitted on 1 Oct 2020

HAL is a multi-disciplinary open access archive for the deposit and dissemination of scientific research documents, whether they are published or not. The documents may come from teaching and research institutions in France or abroad, or from public or private research centers.
L'archive ouverte pluridisciplinaire HAL, est destinée au dépôt et à la diffusion de documents scientifiques de niveau recherche, publiés ou non, émanant des établissements d'enseignement et de recherche français ou étrangers, des laboratoires publics ou privés. 


\title{
Mapping nature-based marine flooding risk using VHR wave, airborne LiDAR and satellite imagery: the case study of the Dol Marsh (Bay of Mont-Saint-Michel, France)
}

\author{
Antoine Mury ${ }^{\dagger *}$, Antoine Collin ${ }^{\dagger}$, Matthieu Jeanson ${ }^{\dagger}$, Dorothée James ${ }^{\dagger}$, Hélène Gloria ${ }^{\dagger}$, Yves Pastol ${ }^{\dagger}$, and \\ Samuel Etienne ${ }^{\dagger \dagger}$. \\ ${ }^{\dagger}$ EPHE, PSL \\ Université Paris, \\ CNRS LETG, \\ Dinard, France \\ ${ }^{\S}$ Laboratoire \\ d'Excellence \\ CORAIL, France \\ ¥UMR 228 ESPACE-DEV, \\ CUFR de Mayotte, \\ Mayotte, France \\ * Naval Hydrographic and \\ Oceanographic Service, \\ Brest, France \\ $\dagger^{\dagger}$ EPHE, PSL \\ Université Paris, \\ EA CHArt, \\ Paris, France
}

\begin{abstract}
A growing interest in nature-based solutions has gained unprecedented attention in the coastal risk management, to complement or replace conventional approaches like hard structures (dykes, seawalls, breakwaters). However, due to the diversity of coastal ecosystems and the heterogeneity of the ecosystem service of wave attenuation they can induce, the integration of their protective role in an accurate way into risk studies remains rare. This paper shows an experimental methodology to integrate this ecosystem service into the risk mapping at very high spatial resolution using in situ sensors, airborne LiDAR and spaceborne satellite imagery. Risk study is achieved using a combination of indices which allows to evaluate the asset's exposure and vulnerability. The nature-based solution is also integrated through the creation of an adaptive capacity index, based on a spatially-explicit model of wave attenuation. The study enables to highlight the assets which are the most concerned by the marine flooding risk, using a synthetic risk index ranging from 0 to 1 .
\end{abstract}

ADDITIONAL INDEX WORDS: Wave, flooding risk, risk exposure, attenuation, spatial modelling.

\section{INTRODUCTION}

Among the consequences of global change, an increase in coastal risks is widely expected in the near future, because of the predicted sea level rise and the storm intensification (IPCC, 2014; Knutson et al., 2010). The low elevation coastal zone (LEZC), defined as the contiguous area along the coast that is less $10 \mathrm{~m}$ above sea level (McGranahan, Balk, and Anderson, 2007), is particularly exposed to the natural hazard of marine flooding, due to its location at the land-sea interface, and its lowland feature. Even if the LEZC represents only two percent of the Earth land surface (McGranahan, Balk, and Anderson, 2007), it hosts 1/10 of the world population and encounters substantial population and urbanization growth rates (Neumann et al., 2015), what increases the exposure and makes the task of coastal risks management a major issue for this attractive zone. The natural risk being commonly defined as the combination of three components which are the hazard, assets exposure, and vulnerability.

Several management methods were implemented to reduce human exposure to coastal hazards, so as to diminish the risk itself. Traditionally, the main tool to mitigate coastal marine flooding risk (preserving humans and their assets) was the systematic utilization of grey engineering (dykes, seawalls, breakwaters; Ballinger, 2014). However, through the many experience feedbacks available about this management method, this way of thinking the coastal risk management has shown its limits and is considered today as economically and ecologically unsustainable (Morris et al., 2018). That is why, green engineering, as a new conceptualization of the coastal risk management based on the natural processes of wave mitigation by intertidal ecosystems, has emerged (Cooper and McKenna, 2008). Mangrove ecosystem rehabilitation programs in tropical LECZ are part of the most significant examples of this renewal of the coastal management (Field, 1999).
To date, the adaptive capacity of coastal ecosystems to reduce the wave hazard (significant wave height and wave energy) is well documented into the literature, both in 1D and 2D (Mury et al., 2019; Shepard, Crain, and Beck, 2011). However, most studies produce $2 \mathrm{D}$ hazard modelling that remains too coarse (several meters in spatial resolution) to elucidate subtle but major water-plant-sediment interactions (Pritchard, Hogg, and Roberts, 2002; Le Hir, Monbet, and Orvain, 2007). Moreover, the integration of the component of the adaptive capacity into the 2D mapping of the marine flooding risk as natural coastal defence structures is also still rare.

This paper presents a methodology for an integrated, seamless mapping of the nature-based flooding risk at very high spatial resolution (VHSR), through the case study of the Dol Marsh in the Bay of Mont-Saint-Michel, France (Fig. 1a). In addition to indicators commonly used when assessing exposure to coastal hazards (distance to shoreline, elevation, slope, built elevation, Martínez-Graña et al., 2016), the nature-based adaptation to the decrease in the risk vulnerability of the humans and assets will be evaluated using a spatially-explicit modelling of the wave attenuation induced by the coastal ecosystems (Mury et al., 2019). This regression modelling will be based on significant wave height measurements and a fusion of satellite multispectral imagery and airborne light detection and ranging (LiDAR) data predictors.

\section{Study site}

The Bay of Mont-Saint-Michel is located deep in the Normandy-Brittany Gulf between the Cotentin Peninsula and the northern coast of Brittany called "Emerald Coast". This bay, subjected to a strong tidal regime, belongs to the top six areas hosting the world's highest tide (Archer, 2013). Provided with a tidal range of approximately $14 \mathrm{~m}$, the intertidal zone extends over an important area of $250 \mathrm{~km}^{2}$. The bay is delimited in the 
south from the lowland of the Dol Marsh polder by the Duchess Anne's dyke (Fig.1) at the foot of which thrive important salt marsh surfaces and numerous sediment deposits, contributing to the coastal protection as natural barriers against waves. Due to its lowland feature, the Dol Marsh is particularly exposed to the marine flood risk (Fig. 1a).

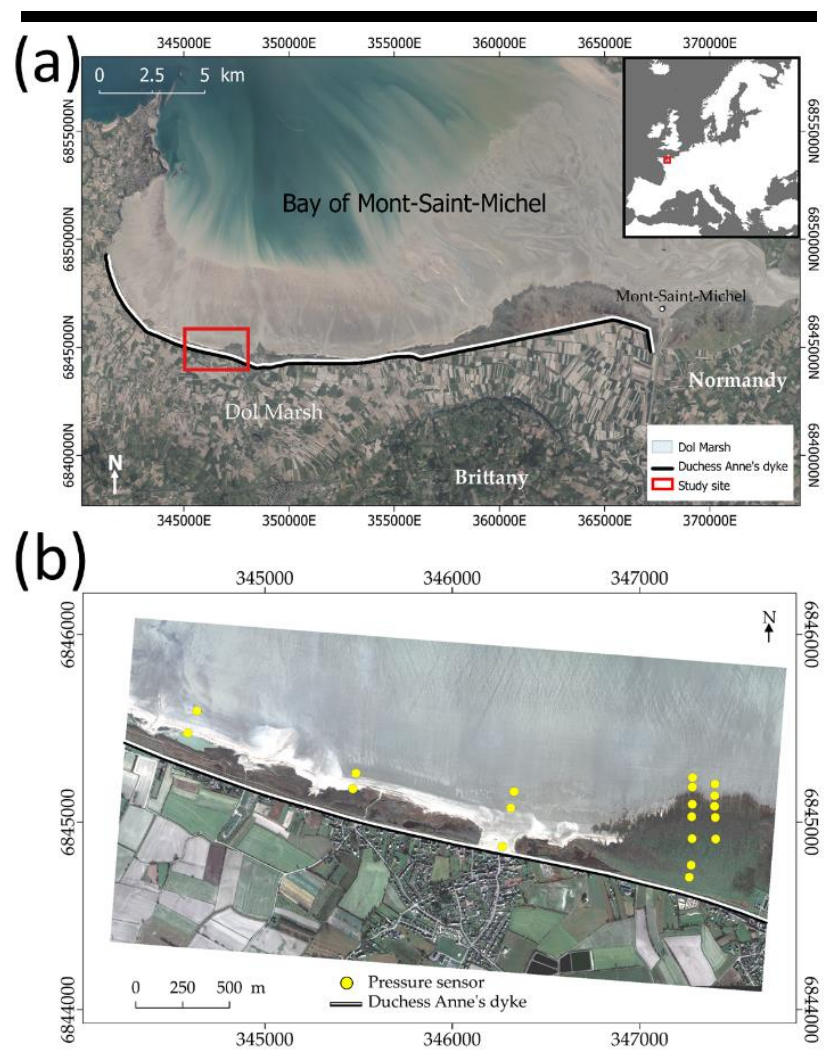

Figure 1. (a) Overview of the study site. (b) Location of the 19 pressure sensors on the study site.

\section{METHODS}

To conduct the mapping nature-based marine flooding risk, different types of data are used in order to analyse the study site, the exposure and the vulnerability of the buildings, to produce preliminary maps for the risk study.

\section{VHR wave measurements}

Significant wave heights ( $\left.\mathrm{Hm}_{0}\right)$ are recorded at VHSR and very high temporal resolution (VHTR) using 19 pressure sensors (NKE SP2T10) distributed along four different cross-shore transects on the study site (Fig. 1b), at a two-Hz frequency, during four consecutive high water ordinary spring tides (approximately 15 million data for each tide cycle). Input $\mathrm{Hm}_{0}$ values on the study site during the acquisition campaign, from January 22 to 23, 2019, range from 0.23 to $0.8 \mathrm{~m}$.

\section{LiDAR data and by-Products}

Six different by-products have been derived from a raw topobathymetric LiDAR data set acquired using a HawkEye-3 sensor (Chiroptera + Deep channel) with topographic horizontal and vertical accuracy of less than $20 \mathrm{~cm}$. Digital elevation, surface, height, infrared intensity, slope and roughness models (DEM, DSM, DHM, DIM, DsM, DRM, respectively) have been created from the original LiDAR point cloud, with a spatial resolution of $0.3 \mathrm{~m} \times 0.3 \mathrm{~m}$

\section{Satellite imagery}

Spaceborne superspectral WorldView-3 (WV-3) imagery, supplied by the European Spatial Agency (ESA), was also used. The WV-3 sensor leverages one panchromatic band and eight optical wavebands (coastal: $400-450 \mathrm{~nm}$ blue: $450-510 \mathrm{~nm}$, green: 510-580 nm, yellow: $585-625 \mathrm{~nm}$, red: $630-690 \mathrm{~nm}$, red edge: 705-745 nm, near-infrared 1 (NIR1): 770-895 nm, near-infrared 2 (NIR2): $860-1040 \mathrm{~nm}$ ) at 0.31 and $1.25 \mathrm{~m}$ pixel size, respectively. The spatial resolution of both optical imageries was scaled up to this of panchromatic using the pan-sharpening procedure (Gram-Schmidt) after conventional radiometric and geometric corrections (see Collin et al., 2019 for further details).

\section{Assets' exposure factors}

The first step of the assets' exposure analysis consists into identifying what is the assets' nature for the study area. Defined as buildings, their identification work is done using a maximum likelihood supervised classification method based on the eight WV-3 multispectral bands and the six LiDAR by-products.

Once the buildings identified, two factors have to be considered following the literature, in order to evaluate the buildings' exposure to marine flooding hazard: distance to shoreline and ground elevation (Martínez-Graña et al., 2016).

The shoreline is defined as the seaward side of the Duchess Anne's dyke and is digitalized by photo-interpretation at a 1/500 scale with an accuracy of $0.30 \mathrm{~m}$, on the WV-3 imagery. All following distances to shoreline are measured using this indicator in order to achieve a shoreline distance-based mapping of the buildings. Ground elevation values are derived from the DEM, to achieve a buildings' elevation mapping.

The exposure mapping results from the combination of both previously-cited mappings:

$$
\text { Exposure }=(\text { Distance to shoreline }+ \text { Elevation }) / 2
$$

\section{Vulnerability factors}

Vulnerability is defined as the ratio of the buildings' sensitivity by the adaptive capacity of the study site:

$$
\text { Vulnerability }=\text { Sensitivity }- \text { Adaptive capacity } / 2
$$

Buildings' sensitivity is evaluated throught several factors like the buildings' height and the presence or absence of anthropogenic protective structures. The adaptive capacity is the ability to the system to adjust to potential damages, and is evaluated by the modelling of the nature-based protection against wave hazards.

Buildings' height values are determined using the difference between DSM and DEM, to achieve a buildings' height mapping, 
in which the higher a building is, the less it is vulnerable to the marine flooding hazard. Here, the sensitivity factor induced by the presence of a hard protective structure is assumed to be a constant because of the presence of the Duchess Anne's dyke all along the study site.

Spatially-explicit modelling of wave attenuation by natural ecogeo-systems, embodying the adaptive capacity, is the spatial representation of a nature-based solution against marine flooding. It is computed from a multiple linear regression between the response of the attenuation rates $(\% / \mathrm{m})$ calculated from the $\mathrm{Hm}_{0}$ previously sampled at VHTR, and the best five spectral and LiDAR predictors, that are NIR1, NIR2, slope, roughness and infrared intensity, extracted from WV-3 imagery and LiDAR byproducts, respectively. The model is defined as follows:

$$
Y=\beta_{0}+\beta_{1} X_{1}+\beta_{2} X_{2}+\ldots+\beta_{n} X_{n}
$$

where $\mathrm{Y}$ is the attenuation value, $\beta_{0}$ a constant, $\beta_{1}$ the coefficient value and $X$ the predictor value. Model accuracy is quantified by the coefficient of determination $\left(\mathrm{R}^{2}\right)$ and its root mean square error (RMSE).

This adaptive capacity is synthetized by using the mean $\mathrm{Hm}_{0}$ attenuation values calculated for each $30 \mathrm{~m} \times 660 \mathrm{~m}$ areas on the seaward side of the Duchess Anne's dyke, and reported as an index ranging from 0 to 1 . This $30-\mathrm{m}$ width area enables to consider that waves are not strictly perpendicular to the shoreline.

\section{Mapping nature-based marine flooding risk}

The risk mapping is the combination of a hazard, several exposure and vulnerability models previously presented. It can be represented by the following formula:

$$
\text { Risk }=\text { Hazard } \cap \text { Exposure } \cap \text { Vulnerability }
$$

All the values of the previously presented models are standardized from 0 to 1 .

\section{RESULTS}

The various methods to evaluate the issues and the study site presented above, allow the creation of spatially-explicit models representing the panel of components and sub-components of the marine flooding risk. Each of these analyses is evaluated using an index from 0 to 1 .

\section{Buildings' exposure mapping}

The buildings' exposure study, as previously presented, is composed of two preliminary steps, which are the analysis of buildings' distance to shoreline and buildings' elevation.

Concerning the analysis of buildings' distance to shoreline, the more the building is close to the shoreline, the more its index is close to 1 . This index ranges from 0.67 to 0.99 (Fig. 2a).

The second component of the buildings' exposure study is the buildings' elevation: equalling to 1 for the lowest elevation point. This elevation index for the buildings ranges from 0.26 to 0.51 (Fig. 2b).
The buildings' exposure, which is one of the main risk components, is also evaluated using a 0 to 1 index. The more the index is close to 1 , the more the building is exposed to marine flooding hazard. In this case study the index ranges from 0.32 to 0.69 (Fig. 2c).

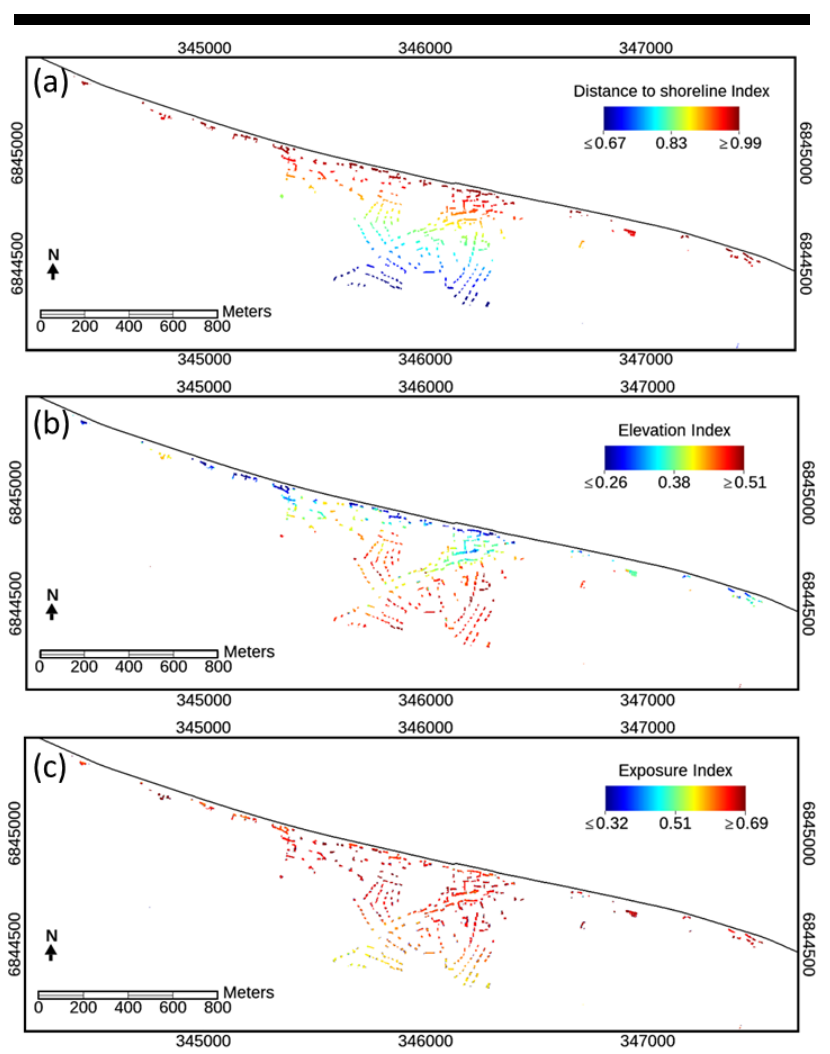

Figure 2. (a) Buildings' distance to shoreline index mapping, (b) Buildings' elevation index mapping, (c) Buildings' exposure index mapping.

\section{Buildings' vulnerability mapping}

The buildings' vulnerability is also a composite product of two factors: the buildings' height and the adaptive capacity.

In the case of the buildings' height study, the more the index is close to 1 , the less vulnerable the building is. Here, the index ranges from 0.66 to 0.91 (Fig. 3a).

The second component of the vulnerability study is the evaluation of the ability of natural eco-geo-systems to adapt to and attenuate potential damages of the $\mathrm{Hm}_{0}$. This ability to reduce the $\mathrm{Hmo}$ is originally evaluated in percentage per meter with the spatially-explicit model of attenuation, between -0.98 (increase in $\mathrm{Hm}_{0}$ ) and 2.01 (Fig. 3b). These attenuation data are incremented into the buildings' vulnerability study through the adaptive capacity index (from 0 to 1 ). Unlike the previous index, the value 1 represents the area which benefits of the best protection. This adaptive capacity index is evaluated between 0.16 and 0.55 (Fig. $3 c)$. 
The combination of the buildings' height index and the adaptive capacity index of buildings allows the construction of a vulnerability index, ranging, here, from 0.40 to 0.86 (Fig. 3d).
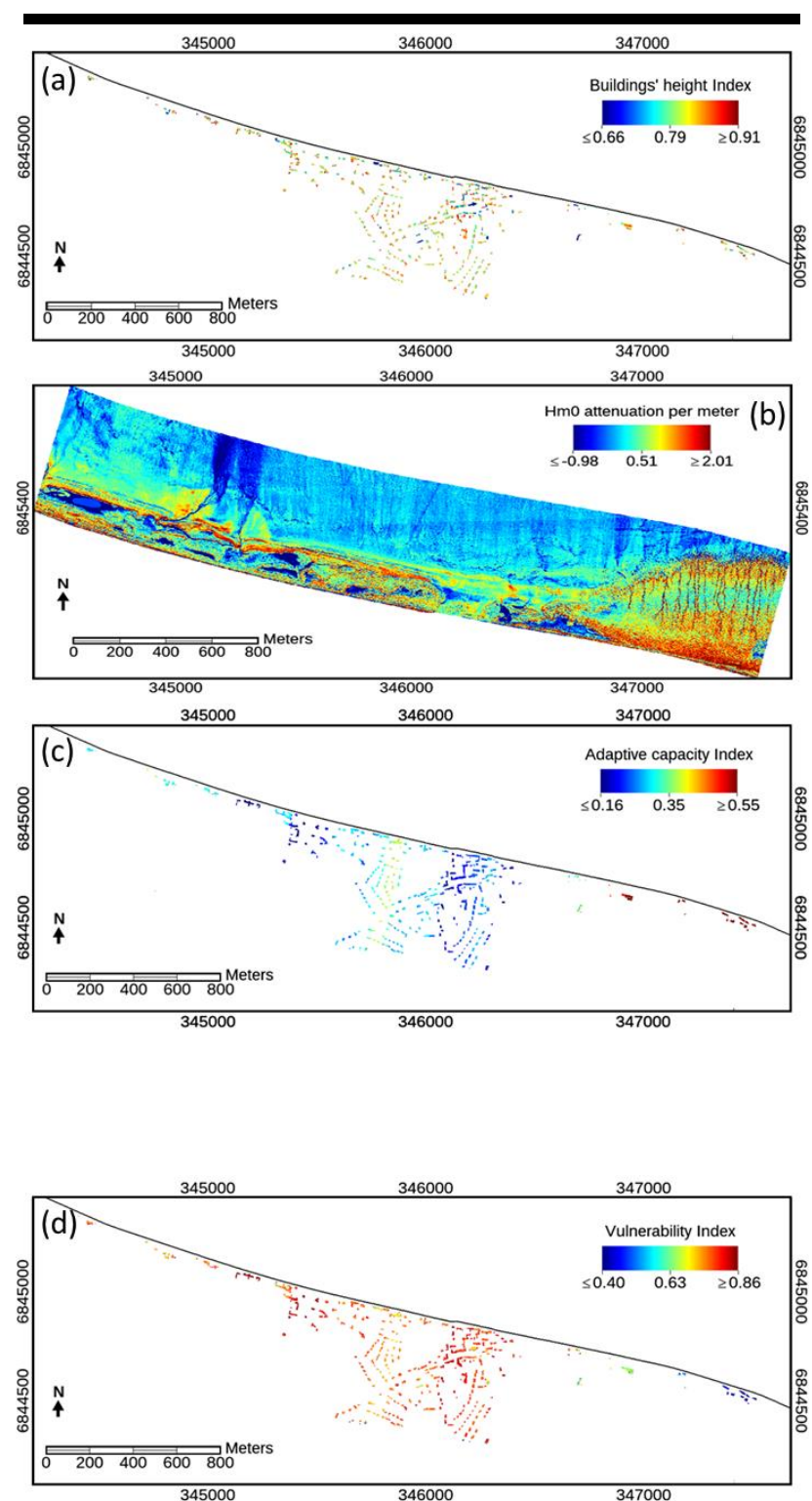

Figure 3. (a) Buildings' height index mapping, (b) Spatially-explicit model of the $\mathrm{Hm} 0$ attenuation (in \% per meter) induced by the coastal eco-geo-systems, (c) Buildings' adaptive capacity index mapping, (d) Buildings' vulnerability index mapping.

\section{Buildings' risk mapping}

The final step of the nature-based marine flooding risk study is the combination of the buildings' exposure index mapping and the buildings' vulnerability index mapping, to implement a risk index mapping. The value 1 represents the area which is the most concerned by the marine flooding hazard. In the Dol Marsh, this risk index ranges from 0.40 to 0.75 (Fig. 4).

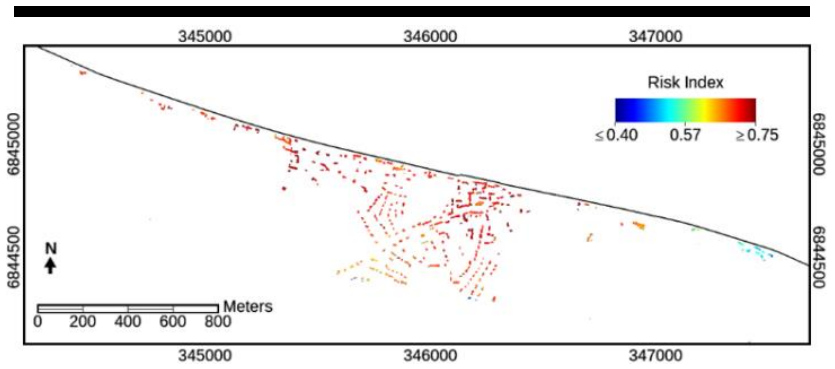

Figure 4. Nature-based marine flooding risk index mapping.

\section{DISCUSSION}

The spatially-explicit models allow to outline the buildings that are the more and the less exposed to the marine flooding hazard. The riskiest building is a one-storey building closed to the shoreline, in a low elevation area, which does not benefit from the natural protection of a coastal ecosystem. The area of the study site that gathers most of these criteria has a risk index of 0.75 , and the part that unifies the least of these criteria has an index of 0.40 .

This VHSR mapping method has a great potential to erect as a useful and accurate decision-support tool in the next years, to better consider the ecosystem service of the coastal risk mitigation, for urban planners. The use of VHSR data allows to properly consider the study site's specificities, especially the micro-topography and variations into plant species zonation, what enables to produce some faithful models of surface, elevation or roughness (Collin, Lambert, and Etienne, 2018).

Nevertheless, this experimental risk mapping methodology has some limitations that could be resolved. The first one is the lack of consideration of the people into the vulnerability definition. Focused on the buildings, the current approach cannot be deemed as a comprehensive methodology. The risk perception by local population is an important factor in the vulnerability component, encouraging some sensitivity studies to be integrated into further investigation (Aerts et al., 2018). The second limitation is the fact that the spatially-explicit modelling of the wave attenuation is based on a reference event, which is time-constrained (e.g., seasonality, wind, atmospheric pressure), conditioning in turn the adaptive capacity index. The third limitation lies in the multiplicity of indices' values for a single building, what could be misunderstood by stakeholders.

\section{CONCLUSIONS}

Various types of data (multispectral satellite imagery, airborne LiDAR and hydrodynamic in situ measurements) and their byproducts, allow to carry out a comprehensive territorial diagnosis, based on the main components of the risk: hazard, exposure and vulnerability, with a very high spatial resolution. These preliminary steps to the risk study (Fig. 4), allow to highlight the different levels of exposure (Fig. 2c) and vulnerability (Fig. 3d) tied with buildings located in a lowland area, like the Dol Marsh. In this study, the most exposed buildings have an exposure index reaching 0.69 and the most vulnerable buildings have a 
vulnerability index topping at 0.86 , on a 0 -to- 1 scale, where 1 is the most exposed or vulnerable index. The achievement of a spatially-explicit model of the wave attenuation induced by the coastal eco-geo-system at VHR (Mury et al., 2019), brings insight to the risk evaluation in comparison to conventional risk analyses by integrating the nature-based protection in an unprecedented way. On the Dol Marsh, the risk index of buildings, which sums up the preliminary indices mapping, ranges from 0.40 to 0.75 (Fig. 4).

\section{ACKNOWLEDGMENTS}

The authors are grateful to the European Space Agency (ESA) for providing the WorldView-3 data imagery, and to the French Naval Hydrographic and Oceanographic Service (SHOM) for the provision of the airborne LiDAR dataset.

\section{LITERATURE CITED}

Archer, A.W., 2013. World's highest tides: Hypertidal coastal systems in North America, South America and Europe. Sediment. Geol., 1-25, 284-285.

Aerts, J.C.J.H.; Botzen, W.J.; Clarke, K.C.; Cutter, S.L.; Hall, J.W.; Merz, B.; Michel-Kerjan, E.; Mysiak, J.; Surminski, S., and Kunreuther, H., 2018. Integrating human behaviour dynamics into flood disaster risk assessment. Nature Climate Change ,8, 193-199.

Ballinger, R., 2014. On the edge: coastal governance and risk. In: Fra Paleo U (ed) Risk governance - the articulation of hazard, politic and ecology. Springer, Dordrecht Heidelberg New York London.

Collin, A.; Lambert, N., and Etienne, S., 2018. Satellite-based salt-marsh elevation, vegetation height, and species composition mapping using the superspectral WorldView-3 imagery. International Journal of Remote Sensing, 39(17), 5619-5637.

Collin, A.M.; Andel, M.; James, D., and Claudet, J., 2019. The superspectral/hyperspatial worldview-3 as the link between spaceborne hyperspectral and airborne hyperspatial sensors: the case study of the complex tropical coast. Int. Arch. Photogramm. Remote Sens. Spat. Inf. Sci., XLII-2/W13, 1849-1854.

Cooper, J.A.G. and McKenna, J., 2008. Working with natural processes: the challenge for coastal protection strategies. The Geographical Journal, 174(4), 315-331.

Field, C.D., 1999. Rehabilitation of mangrove ecosystems: an overview. Marine Pollution Bulletin, 37 (8-12), 383-392.

IPCC, 2014. Climate Change 2014: Synthesis Report; Contribution of Working Groups I, II and III to the Fifth Assessment Report of the Intergovernmental Panel on Climate Change; Core Writing Team, Pachauri, R.K., Meyer, L.A., Eds.; IPCC: Geneva, Switzerland; 151 p.

Knutson, T.R.; McBride, J.L.; Chan, J.; Emanuel, K.; Holland, G.; Landsea, C.; Held, I.; Kossin, J.P.; Srivastava, A.K., and Sugi, M., 2010. Tropical cyclones and climate change. Nat. Geosci., 3, 157-163.

Le Hir, P.; Monbet, Y., and Orvain, F., 2007. Sediment erodability in sediment transport modelling: can we account for biota effects? Continental Shelf Research, 27, 11161142 .
Martínez-Graña, A.M.; Boski, T.; Goy, J.L.; Zazo, C., and Dabrio, C.J., 2016. Coastal-flood risk management in central Algarve: vulnerability and flood risk indices (South Portugal). Ecological Indicators, 71, 302-316.

McGranahan, G.; Balk, D., and Anderson B., 2007. The rising tide: assessing the risks of climate change and human settlements in low elevation coastal zones. Environment Urbanization, 19, 17-37.

Morris, R.L.; Konlechner, T.M.; Ghisalberti, M., and Swearer, S.E., 2018. From grey to green: efficacy of eco-engineering solutions for nature-based coastal defence. Global Change Biology, 24(5), 1827-1842.

Mury, A.; Collin, A.; James, D.; Pastol, Y., and Etienne, S., 2019. Spatially-explicit modelling of the salt marsh wave attenuation using pressure measurements, UAV imagery and LiDAR data. Proceedings, EGU General Assembly Conference, Vienna, Austria, 7-12 April 2019.

Neumann, B.; Vafeidis, A.T.; Zimmermann, J., and Nicholls, R.J., 2015. Future coastal population growth and exposure to sea-level rise and coastal flooding - a global assessment. PLoS ONE, 10(3), e0118571.

Pritchard, D.; Hogg, A.J., and Roberts, W., 2002. Morphological modelling of intertidal mudflats: the role of cross-shore tidal currents. Continental shelf research, 22, 1887-1895.

Shepard, C.C.; Crain, C.M., and Beck, M.W., 2011. The protective role of coastal marshes: a systematic review and meta-analysis. PLoS ONE, 6(11), e27374. 